\title{
Littérature enseignée : reconfigurations du champ
}

\section{Patrick Demougin et Jean François Massol}

\section{(2) OpenEdition}

\section{Journals}

Édition électronique

URL : http://journals.openedition.org/trema/1572

DOI : 10.4000/trema.1572

ISSN : 2107-0997

\section{Éditeur}

Faculté d'Éducation de l'université de Montpellier

\section{Édition imprimée}

Date de publication : 1 octobre 2002

Pagination : 1-2

ISSN : 1167-315X

\section{Référence électronique}

Patrick Demougin et Jean François Massol, «Littérature enseignée : reconfigurations du champ »,

Tréma [En ligne], 19 | 2002, mis en ligne le 01 octobre 2002, consulté le 22 septembre 2020. URL :

http://journals.openedition.org/trema/1572 ; DOI : https://doi.org/10.4000/trema.1572

Ce document a été généré automatiquement le 22 septembre 2020.

Trema 


\title{
Littérature enseignée : reconfigurations du champ
}

\author{
Patrick Demougin et Jean François Massol
}

1 Les troisièmes rencontres des chercheurs en didactique de la littérature se sont déroulées à Grenoble en mars 2002. Fruits de collaborations entre IUFM et Universités, elles faisaient suite aux manifestations organisées précédemment à Rennes et Namur. Nous présentons dans ce numéro quelques-unes des nombreuses et riches communications qui y furent entendues.

2 Ces rencontres sont nées d'un besoin largement ressenti dans la communauté des enseignants et des chercheurs en didactique de la littérature, celui d'un espace d'échange spécifique, qui ne s'impose pas totalement la rigueur des problématiques scientifiques à l'oeuvre dans les colloques, et qui, à l'inverse, ne se borne pas à être un simple lieu informel et convivial de rencontre professionnelle. Les trois sessions tenues à ce jour ont permis de débattre de manière ouverte des questions qui traversent notre discipline et des axes problématiques importants se sont dégagés. En cela, ces rencontres ont atteint leur but : elles ont permis de nouer la réflexion, en situation, dans le cadre de véritables échanges, de faire dialoguer notamment les spécialistes des didactiques de l'enseignement primaire et de l'enseignement secondaire, de confronter les recherches en cours aux questions des praticiens, de faire alterner présentations d'expérimentations et perspectives épistémologiques sur l'avenir de la discipline.

3 Les articles regroupés ici portent sur ce dernier point, fortement présent dans les préoccupations des participants à ces rencontres. Ils évoquent les reconfigurations à l'œuvre dans l'enseignement de la littérature, en terme de pratiques (quelles lectures littéraires proposer, quelles compétences développer?), d'objets (quelles littératures enseignées, quelle place pour l'image ?) et de structure (quelles articulations construire avec les autres éléments du champ disciplinaire Français-Lettres?). Ces questions anciennes traversent le champ disciplinaire avec une actualité renouvelée pour trois raisons que l'on peut rapidement identifier, en fonctions de leurs ancrages respectifs, épistémologique, institutionnel et didactique.

4 La première raison est interne au champ disciplinaire et renvoie aux évolutions propres à l'objet "littérature ». L'apparition de nouveaux horizons critiques au crépuscule des années 70 et la mise en doute du tout « textualiste » fournissent des outils susceptibles de modifier les approches didactiques. Les théories de la réception et la génétique du texte sont les plus popularisés parmi 
ceux-là. La notion même de lecture littéraire, comme l'analyse Jean-Louis Dufays, est l'objet d'une redéfinition dont il précise les contours. Par ailleurs, l'identification de la littérature ellemême, nécessairement historicisée, se trouve soumise au phénomène de classicisation et à ses aléas. La littérature de jeunesse, les littératures populaires, les littératures "étrangères", l'album et la bande dessinée viennent frapper à la porte de la vieille maison, dont il faut refaire l'état des lieux. C'est à cette tâche que s'attelle Gérard Langlade en étudiant la conception restreinte de la littérature qui prévaut dans les situations d'enseignement.

5 L'impulsion politique et les choix effectués qui en découlent dans l'institution scolaire orientent aussi très clairement les questions qui se posent en didactique de la littérature: le renouvellement des programmes, en France, depuis 1995, touche l'école élémentaire, le collège et le lycée. Il aboutit à redéfinir les positions de la langue, de la culture littéraire, de l'image, et les pratiques de lecture et d'écriture. Deux axes se dessinent, dans l'institution scolaire française, l'un centré sur la maîtrise du langage, l'autre sur la culture partagée. La discipline Français Lettres, et tout particulièrement l'enseignement de la littérature, se trouve menacée d'éclatement et doit s'inventer des cohérences nouvelles pour échapper à un double écueil, celui d'une instrumentalisation (une littérature enseignée au service du langage et des valeurs), ou celui, tout aussi dangereux, d'une marginalisation esthétique (une littérature exclusivement enseignée comme art, clivée des autres domaines et tout particulièrement de la question du langage). C'est ce que montrent Annie Rouxel et Jean-Charles Chabanne, en pointant les "chantiers » ouverts par ces nouvelles perspectives, ou encore Françoise Demougin en précisant le rôle que l'image, désormais associée par les programmes au champ littéraire, peut jouer dans une approche renouvelée de l'enseignement de la littérature.

6 Enfin, la recherche en didactique développe ses propres problématiques et leur confrontation au domaine particulier de la littérature, qui ne s'accommode pas d'une simple perspective transpositive, se trouve être féconde. La question du langage et des rapports que le sujet $y$ construit (rapport au savoir, au langage lui-même, aux autres et à soi) apparaît vitale quand on la circonscrit au domaine de l'expérience littéraire. C'est ce que soulignent le travail de Dominique Bucheton sur l'interprétation et la réflexion de Karl Canvat sur la notion de compétence appliquée au champ des études littéraires.

$7 \quad$ Le présent numéro de la revue TREMAentend contribuer, à la suite des troisièmes rencontres des chercheurs en didactique de la littérature, à faire vivre ce débat sur les enjeux d'un enseignement en pleine mutation, celui de la littérature, et sur l'avenir d'une discipline scolaire où se dessinent les ambitions fortes du système éducatif.

\section{AUTEURS}

\section{PATRICK DEMOUGIN}

IUFM de Montpellier, Montpellier III, Didaxis.

\section{JEAN FRANÇOIS MASSOL}

IUFM de Grenoble, Gredilit, Grenoble III, Ecrire 